\title{
Initial Movements of Modern Humans in East Eurasia
}

\author{
Naruya Saitou, Timothy A. Jinam, Hideaki Kanzawa-Kiriyama \\ and Katsushi Tokunaga
}

This contribution discusses three topics touching on the initial movements of modern humans in East Eurasia using genetic data:

1. The emergence of modern humans including the establishment of the 'Sahulian' inhabitants of the Pleistocene continent of Australia and adjacent islands.

2. Negritos as remnants of the initial dispersal to the Southeast Asian region.

3. The descendants of ancient human migration to the Japanese Archipelago.

\section{From the emergence of modern humans to the establishment of Sahulians}

Anatomically modern humans (AMH) are now distributed all over the inhabited planet, and are genetically divided into six major groups: African, West Eurasian, East Eurasian, Sahulian, Northern American, and Southern American (Saitou 1995). It has now been established that AMH originated in Sub-Saharan Africa. Nei and Roychoudhury (1974) estimated the divergence times of three human populations (African, East Eurasian, and West Eurasian) as $c a .120,000$ BP for the African and Eurasian split and $c a .55,000$ BP for the East Eurasian-West Eurasian divergence. Later, Nei and Ota (1991) obtained essentially the same divergence time estimates from the allele frequency data of 181 loci.

More recently, Gronau et al. (2011) estimated somewhat different divergence times from a comparison of six personal genomes; 38,000-64,000 BP years for African and Eurasian divergence, and 31,000-40,000 BP for West Eurasian and East Eurasian divergence. Although the rooted tree topology is the same, the divergence time estimates between Africans and nonAfricans based on classic markers and genome data are rather different. Gronau et al. (2011) also estimated the divergence time of San (bushman) and Yoruba in Nigeria as ca. 150,000 BP when the human-chimpanzee divergence was assumed as 7.6 Mya, and migration between these two populations after their divergence was surmised. If this estimate of human-chimpanzee divergence is a close approximation then the emergence of modern humans would also date to at least $c a$. 150,000 BP. 
Human movements during the 'Out-of-Africa' dispersal possibly started via coastal routes (e.g. Macaulay et al. 2005). If we connect the coastlines in present-day Tanzania and the northern reaches of Australia, the total length across land is less than $40,000 \mathrm{~km}$. If AMH migrated along this coastal route using raft-like boats, they could have arrived at present-day Australia within 110 years, assuming an average forward movement of $1 \mathrm{~km}$ per day. If they encountered any reason to halt progressive movement and abandon the fringes of occupied territory, they could have simply backtracked to their homeland by following the same coastline. The adventurous colonists who continued to move south and east would have passed down the Thai-Malay Peninsula and overland across 'Sundaland' as far as Borneo and Bali, and then traversed the islands of eastern Indonesia before eventually settling in Sahul. Their descendants became Australian Aborigines and Melanesians (including some of the present-day inhabitants of New Guinea, the islands of the Bismarck and Solomon archipelagos, Australia and Tasmania).

\section{Negritos as remnants of secondary dispersal within the Indo-Pacific Ocean area}

Until the Holocene (starting $c a$. 11,000 BP), the present-day islands of Sumatra, Java and Borneo were joined together with the Asian mainland, forming a landmass known as Sundaland (Bellwood and Glover 2004). Sundaland was separated from Sahulland by multiple islands referred to as Wallacea. Several human populations with characteristic morphological features in the Andaman Islands, the Philippines, and Peninsular Malaysia are collectively known as 'Negritos'. These Negritos may be remnants of early AMH dispersals within Island Southeast Asia postdating the initial colonisation of Sahulland.

Omoto and his collaborators studied Philippine Negritos using classic genetic polymorphism markers such as blood groups, red cell enzymes, and serum proteins (Omoto et al. 1978; Omoto 1981, 1985). A phylogenetic tree shown in Omoto (1981) suggests that the Philippine Negritos diversified after the Sahulians split off from Eurasians but before the majority of East Eurasian lineages diversified. Omoto (1985) also demonstrated that the Mamanwa, a Negrito population found on Mindanao Island, appear to be quite different from other Negrito groups in the Philippines. We are now conducting genome-wide SNP data analysis of these Philippine Negritos typed by one of us (Katsushi Tokunaga) as well as those for Malaysian and Andamanese Negritos, and have found some shared components among these populations (Jinam et al. 2013).

Jinam et al. (2012) conducted a genetic analysis of Southeast Asian populations using SNP data from PASNP (HUGO Pan-Asian Consortium 2009) and HGDP-CEPH panel database (www.cephb.fr/), together with newly generated complete mitochondrial DNA (mtDNA) sequences in four indigenous Malaysian groups, and compared them with other populations. These include three Austronesian groups (Temuan, Seletar, and Bidayuh) and a Negrito group (Jahai). Negritos in the Thai-Malay Peninsula currently speak Austro-Asiatic languages, but this is attributed to 'language switch' following the mid-Holocene incursion of early AustroAsiatic populations into the Peninsula. Complete mtDNA sequences were newly determined from 86 individuals (24 Jahai, 18 Temuan, 21 Seletar and 23 Bidayuh). These sequence data are available from the DDBJ/EBA/GenBank International Nucleotide Sequence Databases accession nos AP012346-AP012431. All individuals were assigned to specific haplogroups belonging to $\mathrm{M}$ and $\mathrm{N}$ macro-haplogroups by following the nomenclature in these databases (www.phylotree.org).

Principal Component Analysis (PCA) was performed using haplogroup frequencies from this study and from selected populations available in the literature. The PCA plot shown in Figure 2 of Jinam et al. (2012) shows that Negrito populations (Jahai, Kensiu, Batek and Mendriq) and one 
non-Negrito population in the Thai-Malay Peninsula (Temuan) are clearly separated from other Southeast Asian populations in terms of their PC1 coordinates. Interestingly, the population closest to this 'Peninsula Negrito' cluster is Papuan. This suggests some level of shared ancestry between Peninsula Negritos and Papuans. Five other (non-Papuan) populations, which are close to the 'Peninsula Negrito' cluster, are non-Negrito populations in the Thai-Malay Peninsula and the Philippine Negrito Mamanwa. This result also suggests some level of shared ancestry between Peninsula and Philippine Negrito populations.

Phylogenetic trees of $\mathrm{M}$ and $\mathrm{N}$ mtDNA macro-haplogroups are shown in Figures $3 \mathrm{~A}$ and $3 \mathrm{~B}$ of Jinam et al. (2012), and the coalescence time estimates of selected haplogroups based on mtDNA coding-region sequences are shown in Table 3 of Jinam et al. (2012). These results show that the mtDNA lineages of all three populations living in the Thai-Malay Peninsula coalesce with mtDNA sequences found from other geographical areas, and their coalescence time estimates are older than 10,000 years ago.

Jinam et al.'s (2012) study included the first description of mtDNA diversity in four indigenous Thai-Malay Peninsula populations using complete sequence data from all sampled individuals. This is in contrast to most studies in which complete mtDNA sequencing was performed only on selected haplotypes based initially on control region diversity. Such biased sampling can lead to exaggerated results in some analyses as demonstrated by Gunnarsdottir et al. (2011).

Jinam et al. (2012) also analysed genome-wide $(-50,000$ SNP) data for 17 human populations that are mainly located in Southeast Asia. Those data were retrieved from the Pan-Asian SNP database (www4a.biotec.or.th/PASNP) based on the paper by HUGO Pan-Asian SNP Consortium (2009). PC1 of the PCA plot shown in Figure 4A of Jinam et al. (2012) clearly separates Melanesian from the other populations. The Alorese in east Indonesia are closest to Melanesian, suggesting some gene flow between them if we consider their geographical propinquity. Philippine Negritos lie between Alorese and other populations, and this suggests some degree of shared common ancestry. Thai-Malay Peninsula Negritos are quite different from all other populations in terms of PC2 coordinates. When these four outlier populations (Melanesians, Alorese, Philippine Negritos, and Peninsula Negritos) are eliminated from comparison, the remaining 13 populations are now well scattered in a circular structure as shown in Figure 4B of Jinam et al. (2012). The Bidayuh in Borneo and the Temuan in the Thai-Malay Peninsula both show a 'comet-like' pattern (named by Jinam et al. 2012), which suggests recent admixture with surrounding populations. The locations of the other 11 populations on this PCA plot are as follows (counter-clockwise): Indigenous Taiwanese, Filipino, Mentawai, Sulawesi, Sumatran, Malay, Dayak, Javanese, Cambodian, Thai, and South Chinese. This constellation of populations is more or less consistent with the 'Out-of-Taiwan' model for the origins of people who speak Austronesian languages (Bellwood 2005, 2007).

A phylogenetic network of 17 human populations mainly from Southeast Asia, which was drawn by using Neighbor-Net (Bryant and Moulton 2004), is shown in Figure 2.1 (modified from Figure 5B of Jinam et al. 2012). Consistent with the PCA plot (Figure 4A of Jinam et al. 2012), Melanesians fall well apart from all other populations, although Alorese are closest to Melanesians because they are separated from the other 15 populations at split 'a'. Interestingly, split 'b' links Melanesians and Philippine Negritos. Splits 'a' and 'b' are incompatible with each other, and a parallelogram is formed to represent the reticulated structure. These splits suggest different types of shared ancestry or outcomes of recent Alorese-Melanesian admixture and Philippine Negrito-Melanesian admixture. Splits ' $c$ ' and ' $d$ ' are also incompatible, as the former indicates genetic similarity between the Temuan and Peninsula Negritos, while the latter 
clusters Peninsula Negritos, Philippine Negritos, Alorese, and Melanesians. The dichotomy of populations suggested by split ' $\mathrm{d}$ ' may correspond to two major waves of human dispersals to Southeast Asia and Oceania.

The paper by Jinam et al. (2013), which was included in the special Human Biology issue on Negritos (Endicott 2013), analysed admixture patterns between two Peninsula Negrito groups (the Jahai and Kensiu) and surrounding populations. It found traces of recent admixture in both Negrito populations, particularly the Jahai. It also identified significantly differentiated nonsynonymous SNPs and haplotype blocks related to intracellular transport, metabolic processes, and detection of stimulus. These results highlight the different levels of admixture experienced by the two Malaysian Negrito populations.

If we examine external edge lengths for each population in Figure 2.1, most of the populations with large population size have short lengths, such as Southern Chinese, Thai, Javanese, Malays and Filipinos. In contrast, populations with small population sizes tend to have long exterior edge length, such as Aboriginal Taiwanese, Mentawai in Sumatra, Dayak and Bidayuh in Borneo, Temuan in Malay Peninsula, and Peninsula and Philippine Negritos. A possible exception is Cambodians; although they have a large population size, their exterior edge length is quite long. This suggests a unique history of the Cambodian population. It should also be noted that populations who experienced admixture in the past, such as the Japanese of Japan's central islands, also tend to have short external edge lengths, as indicated by the Japanese Archipelago Human Population Genetics Consortium (2012).

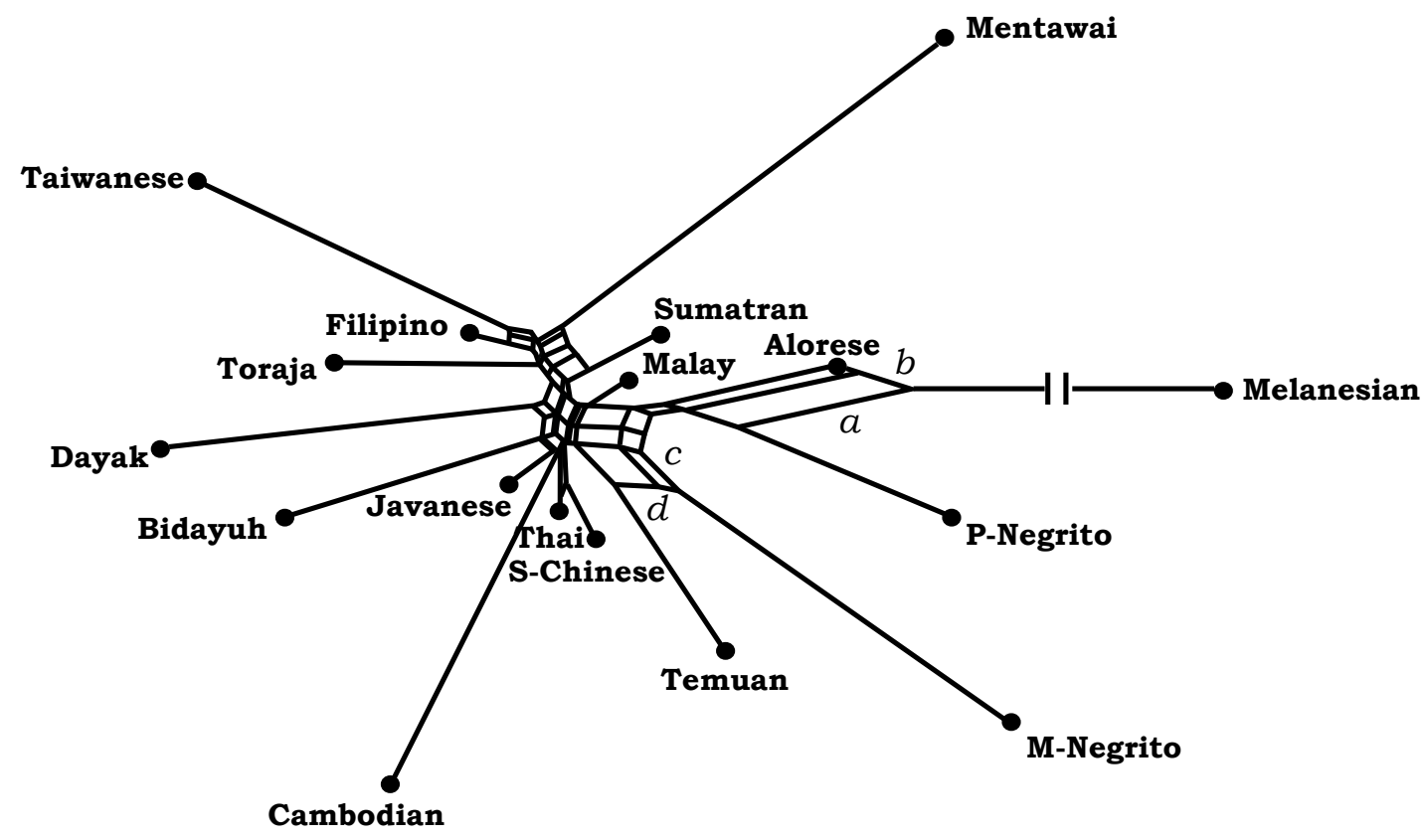

Figure $2.1 \mathrm{~A}$ phylogenetic network of 17 human populations based on genome-wide SNP data.

Source: Modified from Jinam et al. 2012. 


\section{Descendants of ancient human migrants to the Japanese Archipelago}

After modern humans initially migrated into Sundaland and then Sahulland, their movements northward reached the Japanese Archipelago, which has been populated for more than $40 \mathrm{Kya}$ (Imamura 1996). The Jomon people were Neolithic hunter-gatherers who inhabited the Japanese Archipelago from $c a$. 16,000 BP to $3000 \mathrm{BP}$ (Harunari and Imamura 2004). The Jomon culture is defined by the presence of cord-marked ('jomon' in Japanese) pottery, and ranged geographically from Hokkaido to the Okinawa islands, stretching over $4,000 \mathrm{~km}$ from north to south. The archipelago was essentially disconnected from continental East Eurasia, by the end of the last glacial period, from $c a$. 12,000 BP. The Jomon people were probably genetically isolated from continental East Eurasians after that time. Craniofacial data suggests that the ancestors of the Jomon came from somewhere in Southeast Asia (Hanihara 1991), while classic genetic marker data (Omoto and Saitou 1997) and mtDNA sequence data (Adachi et al. 2011) suggest a northern origin. Interestingly, the so-called Jomon mtDNA haplotypes (M7a and N9b) are rarely observed in other modern East Eurasians (Adachi et al. 2011). Therefore, the origins of the Jomon people and their genetic relationship with other modern humans are still unclear.

Kanzawa-Kiriyama et al. (2013) determined the mtDNA haplotypes of four individuals excavated from the Sanganji shell mound in Fukushima, Tohoku district, Japan, dating to the late and final Jomon Period, between 4000-2500 BP. The haplogroup frequencies were 50 per cent for N9b and 50 per cent for M7a2. Haplogroup N9b had previously been observed at high frequencies in other Tohoku Jomon fossils and Hokkaido Jomon fossils, as well as the Okhotsk and Ainu peoples, whereas its frequency is reported to be low in Kanto Jomon fossils and the modern Japanese of the central islands. Sub-haplogroup M7a2 has previously been reported in Hokkaido Jomon fossils, and the Okhotsk and modern Udegey peoples, but not amongst Kanto Jomon fossils, or the Ainu or Ryukyu peoples.

Kanzawa-Kiriyama et al. (2013) also compared mtDNA haplogroup frequencies of Jomon fossils from three areas (Tohoku, Hokkaido, and Kanto) and 15 present-day East Asians. The phylogenetic network using Neighbor-Net (Bryant and Moulton 2004) based on Fst values is shown in Figure 2.2 (from Figure 4 of Kanzawa-Kiriyama et al. 2013). Interestingly, the Tohoku and Hokkaido Jomon populations appear to be closely related, while the Kanto Jomons are obviously distinct. The Udegey of Southern Siberia, who live near the Japan Sea, are relatively closer to Tohoku and Hokkaido Jomon. The reticulation suggests that the Udegey represent an admixture of southern Siberian populations and the northern Jomon people.

It should be noted that mtDNA is a single locus, and its genetic information is very limited even if its complete genomic sequence is obtained. We have therefore proceeded to determine nuclear DNA sequences that are much larger than mtDNA. The results (Kanzawa-Kiriyama et al. 2017) clearly indicate that the present-day Japanese have inherited the DNA of Jomon people, as best represented by the Ainu who are direct descendants of the Jomon. This confirms Hanihara's (1991) dual structure model and the conclusion of Japanese Archipelago Human Population Genetics Consortium (2012). 


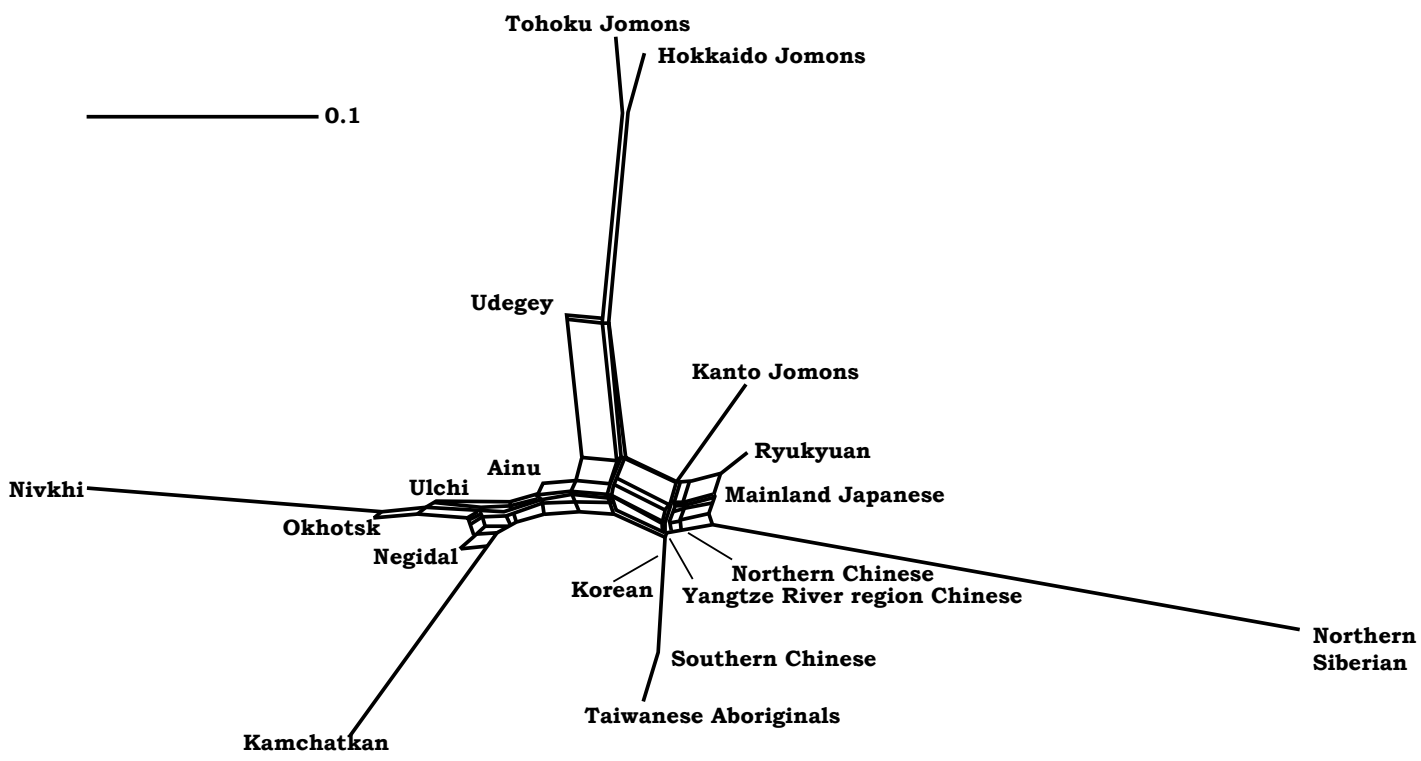

Figure 2.2 A phylogenetic network of three ancient Jomon populations and 15 present-day populations based on mtDNA haplotype frequencies. Scale bar represents the genetic distance between populations based on mitochondrial DNA haplotype frequencies.

Source: From Kanzawa-Kiriyama et al. 2013; published with the permission of the Anthropological Society of Nippon.

\section{Acknowledgements}

This study is supported by a SOKENDAI strategic research grant given to Naruya Saitou and in part by a Grant-in-Aid in 2011-2015 (no. 23247040) and 16H02527 (P.I. of both grants are Hirobumi Matsumura) from the Japan Society for the Promotion of Science.

Authors are grateful to Dr Hirofumi Matsumura who gave us the opportunity to contribute this paper to this book.

\section{References}

Adachi, N., K.-i Shinoda, K. Umetsu, T. Kitano, H. Matsumura, R. Fujiyama, J. Sawada and M. Tanaka. 2011. Mitochondrial DNA analysis of Hokkaido Jomon skeletons: remnants of archaic maternal lineages at the southwestern edge of former Beringia. American Journal of Physical Anthropology 146: 346-360.

Bellwood, P.S. 2005. First Farmers: The Origins of Agricultural Societies. Malden, MA: Blackwell.

- 2007. Prehistory of the Indo-Malaysian Archipelago. 3rd edition. Canberra: ANU E Press.

Bellwood, P. and I. Glover. 2004. Southeast Asia: Foundations for an Archaeological History. In I. Glover and P. Bellwood (eds), Southeast Asia: from Prehistory to History, pp. 4-20. Oxford, UK: Routledge.

Bryant, D. and V. Moulton. 2004. Neighbor-net: an agglomerative method for the construction of phylogenetic networks. Molecular Biology and Evolution 21: 255-265. doi.org/10.1093/molbev/ msh018.

DDBJ/EBA/GenBank International Nucleotide Sequence Databases www.phylotree.org. 
Endicott, P. (ed.). 2013. Special issue on revisiting the 'Negrito' Hypothesis. Human Biology vol. 85, issues 1-3.

Foundation Jean Dausset, Le panel HGDP-CEPH (Human Genome Diversity Panel-Centre d'Etude du Polymorphisme Humain), www.cephb.fr/.

Gronau, I., M.J. Hubisz, B. Gulko, C.G. Danko and A. Siepel. 2011. Bayesian inference of ancient human demography from individual genome sequences. Nature Genetics 43: 1031-1035. doi. org/10.1038/ng.937.

Gunnarsdottir, E.D., M. Li, M. Bauchet, K. Finstermeier and M. Stoneking. 2011. High throughput sequencing of complete human mtDNA genomes from the Philippines. Genome Research 21: 1-11. doi.org/10.1101/gr.107615.110.

Hanihara, K.1991. Dual structure model for the population history of the Japanese. Japan Review 2: 1-33.

Harunari, H. and M. Imamura (eds). 2004. Real Age of Yayoi Period. Tokyo: Gakusei Sha (in Japanese).

HUGO Pan-Asian SNP Consortium. 2009. Mapping human genetic diversity in Asia. Science 326: 1541-1545. doi.org/10.1126/science.1177074.

Imamura, K. 1996. Prehistoric Japan: New Perspectives on Insular East Asia. Honolulu: University of Hawaii Press.

Japanese Archipelago Human Population Genetics Consortium (Consortium members: Jinam, T., N. Nishida, M. Hirai, S. Kawamura, H. Oota, K. Umetsu, R. Kimura, J. Ohashi, A. Tajima, T. Yamamoto, H. Tanabe, S. Mano, Y. Suto, T. Kaname, K. Naritomi, K. Yanagi, N. Niikawa, K. Omoto, K. Tokunaga and N. Saitou). 2012. The history of human populations in the Japanese Archipelago inferred from genome-wide SNP data with a special reference to the Ainu and the Ryukyuan populations. Journal of Human Genetics 57: 787-795. doi.org/10.1038/jhg.2012.114.

Jinam, T.A., L.-C. Hong, M.A. Phipps, M. Stoneking, M. Ameen, J. Edo, Pan-Asian SNP Consortium, and N. Saitou. 2012. Evolutionary history of continental South East Asians: 'early train' hypothesis based on genetic analysis of mitochondrial and autosomal DNA data. Molecular Biology and Evolution 29: 3513-3527. doi.org/10.1093/molbev/mss169.

Jinam, T.A., M.A. Phipps and N. Saitou. 2013. Admixture patterns and genetic differentiation in Negrito groups from West Malaysia estimated from genome-wide SNP data. Human Biology 85(1): Article 8. doi.org/10.3378/027.085.0308.

Kanazawa-Kiriyama H., A. Soso, G. Susa and N. Saitou. 2013. Ancient mitochondrial DNA sequences of Jomon teeth samples from Sanganji, Tohoku district, Japan. Anthropological Science 121: 89-103. doi.org/10.1537/ase.121113.

Kanzawa-Kiriyama H., K. Kryukov, T.A. Jinam, K. Hosomichi, A. Saso, G. Suwa, S. Ueda, M. Yoneda, A. Tajima, K. Shinoda, I. Inoue and N. Saitou. 2017. A partial nuclear genome of the Jomons who lived 3,000 years ago in Fukushima, Japan. Journal of Human Genetics 62(2): 213-221. doi. org/10.1038/jhg.2016.110.

Macaulay, V., C. Hill, A. Achilli, C. Rengo, D. Clarke, W. Meehan, J. Blackburn, O. Semino, R. Scozzari, F. Cruciani, A. Taha, N.K. Shaari, J.M. Raja, P. Ismail, Z. Zainuddin, W. Goodwin, D. Bulbeck, H.J. Bandelt, S. Oppenheimer, A. Torroni and M. Richards. 2005. Single, rapid coastal settlement of Asia revealed by analysis of complete mitochondrial genomes. Science 308: 1034-1036. doi.org/10.1126/science.1109792. 
Nei, M. and A. Roychoudhury. 1974. Genetic variation within and between the three major races of man, Caucasoids, Negroids, and Mongoloids. American Journal of Human Genetics 26: 421-443. doi. org/10.1007/978-4-431-68302-5_26.

Nei, M. and T. Ota. 1991. Evolutionary relationships of human populations at the molecular level. In S. Osawa and T. Honjo (eds), Evolution of life, pp. 415-428. New York: Springer-Verlag.

Omoto, K. 1981. The genetic origins of the Philippine Negritos. Current Anthropology 22: 421-422. doi. org/10.1086/202696.

1985. The Negritos: genetic origins and microevolution. In R. Kirk and E. Szathmary (eds), Out of Asia: Peopling the Americas and the Pacific, pp. 123-131. Canberra: The Journal of Pacific History.

Omoto, K. and N. Saitou. 1997. Genetic origins of the Japanese: A partial support for the dual structure hypothesis'. American Journal of Physical Anthropology 102: 437-446. doi.org/10.1002/(SICI)10968644(199704)102:4<437::AID-AJPA1>3.0.CO;2-P.

Omoto, K., S. Misawa, J.S. Sumpaico, P. M. Medado and H. Ogonuki. 1978. Population genetic studies of the Philippine Negritos. I. A pilot survey of red cell enzyme and serum protein groups. American Journal of Human Genetics 30: 190-201.

Saitou, N. 1995. A genetic affinity analysis of human populations. Human Evolution 10: 17-33. doi. org/10.1007/BF02437511.

van Oven, M., M. Kayser. 2009. Updated comprehensive phylogenetic tree of global human mitochondrial DNA variation. Hum Mutat 30(2): E386-E394, www.phylotree.org. doi.org/10.1002/ humu.20921. 
This text is taken from New Perspectives in Southeast Asian and Pacific Prehistory, edited by Philip J. Piper, Hirofumi Matsumura and David Bulbeck, published 2017 by ANU Press, The Australian National University, Canberra, Australia. 